\title{
Triumphs and Despair -Journey of Health Prospect from Newsletter to Peer Reviewed Journal
}

\author{
Mishra SR, ${ }^{1}$ Katuwal S, ${ }^{1}$ Mahato NK ${ }^{1}$ \\ ${ }^{1}$ Journal Office \\ Health Prospect, Volume 11, Nepal
}

Science is a body of reliable knowledge .It cannot survive without communication. Scientists communicate their ideas through their scholarly papers in a scientific journal. A scientific journal is a periodical publication intended to further the progress of science, usually by reporting new research. It is an undisputed fact that scientific progress serves as a development indicator of any nation where scientific journal publication serves for national development. The history of scientific journals dates back to 1665 ADwhen the French Journal des sçavans and the English Philosophical Transactions of the Royal Society first began systematically publishing research results(1), but the trend to publish scientific journal in Nepal started only in the early 1960's and that in life-sciences started on September 1963 under the editor in chief of Dr. Mrigendra Raj Pandey published by Nepal Medical Association (NMA).(2) From then to now, 43 published life-science journals has been listed in Journal Bibliography in Nepal (NepJol) including Health Prospect, an annual peer reviewed Journal of Nepal Public Health Students' Society (NPHSS).

Established in 1988 A.D Nepal Public Health Students' Society (NPHSS) is an umbrella organization of Public Health Students. It is non-governmental, non- political and nonprofit making and is managed by Public Health students at Institute of Medicine (IOM) to ensure their educational rights and responsibilities as Public Health Students. Since then it has been advocating issues of public health importance and creating awareness through the involvement of energetic students with the conductino of different public health activities.

Health Prospect began its journey as Newsletter in 2000 AD. At that time, it was quarterly publication convering NPHSS activities, students scholarly papers in public health. The initial two years in the journey of health prospect built good foundation. It was highly praised by students, faculties of Institute of Medicine and young public health professionals . It was quite famous among the students in Institute of Medicine. It become the voice of public health students, where they can express their scholarly thoughts and creative ideas. As the year passed, they felt the need to build health Prospect further into a magazine that could provide more space to foster their ideas.Health Prospect refined itself year by year. Quickly, newsletter grew into magazine in 2002 AD. Every work in Health Prospect was voluntary and there were little funds to sustain its publication. Funds were raised through selling and public health related advertisements in publication. But there were lag in between 2008-10 due to insufficiency of funds for publication of Health Prospect. There was single publication of health prospect in the three years. Students felt strong despair as their voice was frozen and something so important to them was missing from years.

The entire publication work was a difficult task. Students worked in different committees for editing; fund raising, and designing so synchronized and so voluntarily that their lust for Health Prospect could bee asily felt. Time and again, students felt strong desire to make health prospect a better space for publication of their academic research, scholarly reviews and viewpoints. This led to the publication of Health Prospect as a peer reviewed Journal in print and online on NepJol from December, 2011. For the publication of journal, peer review committee was organized, editorial committee was set inviting experts from different domains of public health. Sound peer review and editing was done to increase the quality of journal and its content. The next triumph was issue of International Standard Serial Number (ISSN) for Health Prospect. The ISSN is an eight-digit number which identifies periodical publications as such, including electronic serials.

There are always opportunities and challenges behind good initiatives. Challenges become more pronounced and opportunities seem deemed at times when it is set forth from students. The best thing of student life what we like the most is that we have the freedom to make mistakes, opportunities to correct, courage to challenge any hurdles. I believe this initiative ought to get better day by day. Health Prospect is that initiative-set forth midst of challenges to exploit the opportunities that it will create for students and young professionals.

CORRESPONDENCE: Shiva Raj Mishra,Journal Office, Health Prospect Volume 11, Kathmandu Nepal. Email: shivarajmishra@gmail.com 


\section{References}

1. Wikimedia FI. Scientific journal. www.wikipedia.org; 2012 [cited 2012 December 31]; Available from: http:// en.wikipedia.org/wiki/Scientific_journal.

2. Shrestha R. Life Science Journals published in Nepal - An overview. Kathmandu: www.wordpress.com; 2012 [cited 2012 December 31]; Available from: http:// raunakms.wordpress.com/2011/07/22/life-science-journalspublished-in-nepal-an-overview/. 